rev.relac.int.estrateg.segur.13(1):67-92,2018

\title{
Nociones de seguridad y control en el Plan Frontera Norte: una expresión de teichopolítica*
}

\author{
Gilberto Aranda** \\ Cristian Ovando***
}

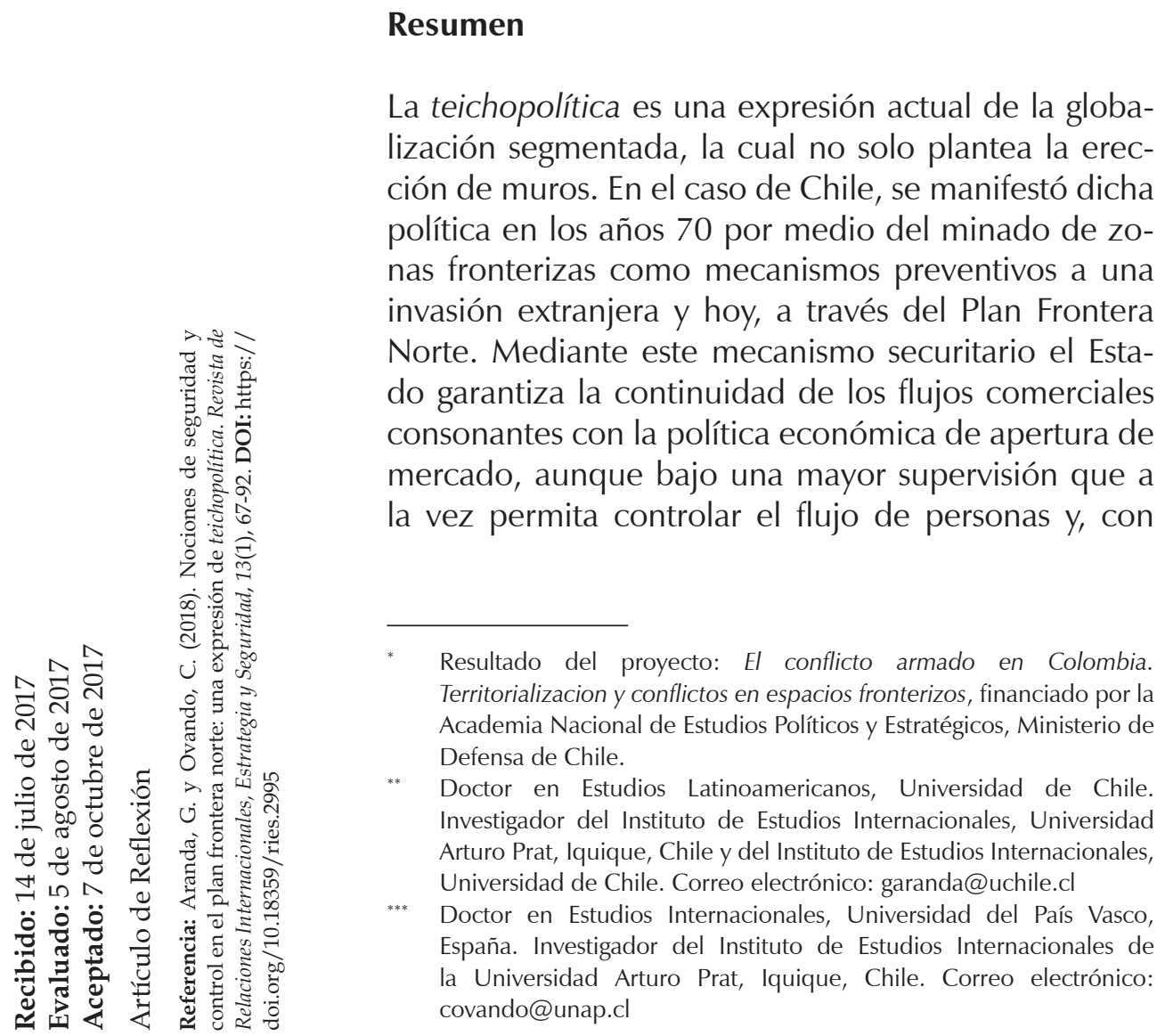


especial atención, contener el tráfico ilegal de mercancías y narcóticos. El Estado también expresa consecuencias culturales hacia la otredad que deben ser tenidas en cuenta. Este artículo tiene por objetivo revisar la implementación de dicho plan como expresión de teichopolítica; para ello se hace una revisión de conceptos y términos desde una perspectiva constructivista. Asimismo, indaga en algunos aspectos del contenido de política pública que involucra. Se concluye que la evaluación del programa da cuenta más de la inversión concretada que del impacto que ha tenido en las estadísticas de decomisos de drogas y procedimientos policiales asociados al tráfico de drogas ilícitas. Lo anterior también se refleja en los informes y el análisis del Ministerio del Interior que solo consigna el nivel de inversión en equipamiento y dotación policial.

Palabras clave: Tarapacá; Arica; Parinacota; securitización; Plan Frontera Norte; teichopolítica.

\title{
Notions of safety and control to Northern Border Plan: an expression of teichopolitics
}

\begin{abstract}
Teichopolitics is a current expression of the segmented globalization, which not only raises the erection of walls. In Chile's case, this policy was manifested in the 1970's through the mining of limiting areas as defensive mechanisms for a foreign invasion and today, by the Northern Border plan. Employing this security mechanism, the State guarantees the continuity of financial flows consonant with the economic policy of market opening, although under a greater supervision that at the same time allows for the control the flow of people and, with particular attention, to contain the illegal traffic of goods and narcotics. The State also express cultural consequences for the otherness that must be taken into account. This article aims to review the implementation of this plan as an expression of Teichopolitics, for this end, a revision of concepts and terms is made from a constructivist perspective. Also, it investigates in some aspects of the content of the public policy that it involves. It is concluded that the evaluation of the program gives more account of the actual investment than of the impact that these investments have had on statistics of drug seizures and police procedures associated with illicit drug trafficking. This is also reflected in the reports and analyses from the Ministry of the Interior that only declares the level of investment in equipment and police resources.
\end{abstract}

Keywords: Tarapaca; Arica; Parinacota; securitization; Northern Border Plan; teichopolitics. 


\section{Noções de segurança e controle no Plano Fronteira Norte: uma expressão da teichopolítica}

\section{Resumo}

A teichopolítica é uma expressão conhecida na globalização segmentada. Nesse sentido, ela não propõe somente a construção de muros. No caso do Chile, manifestou-se tal política nos anos 70 por meio de minado de zonas de fronteiras como mecanismos preventivos a uma invasão estrangeira e hoje, através do Plano Fronteira Norte. Através deste mecanismo de segurança, o Estado garante a continuidade do comércio consequente com a política de abertura do mercado, embora sob uma supervisão que permita controlar o fluxo de pessoas com especial atenção na contenção do tráfico ilegal de bens e narcóticos. O Estado expressa também consequências culturais consideraveis no outro. Este trabalho tem por objetivo revisar a implantação do plano como uma expressão da Teichopolítica. Para isso será feita uma revisão de conceitos e termos desde uma perspectiva construtivista. O trabalho também pesquisa alguns aspectos do conteúdo das políticas públicas envolvidas. Conclui-se da avaliação do programa, que este mostra mais o investimento feito do que o impacto nas estatísticas de apreensões de drogas e procedimentos policiais referentes ao tráfico de drogas ilegais. Isto, também se reflete nos relatórios e análises do Ministério do Interior quem só salienta o nível de investimento em equipamento e polícia.

Palavras-chave: Tarapacá; Arica; Parinacota; securitización; Plano Fronteira Norte; teichopolítica.

\section{Introducción}

El Norte Grande Chile, y particularmente las regiones de Arica y Parinacota, más Tarapacá, han estado sujetas a reclamos y demandas por parte de estados vecinos, por lo que las temáticas de defensa y seguridad tradicionalmente miraron dichas zonas como áreas sensibles y de especial atención. Desde fines del siglo $\mathrm{XX}$, la inmigración y el tráfico de estupefacientes -fenómenos distintos, desde luego- han resemantizado la noción de seguridad transfronteriza. Este artículo tiene por objetivo específico revisar la implementación del Plan Frontera Norte como expresión de teichopolítica, es decir, un dispositivo securitario destinado a filtrar/seleccionar el tipo de intercambio que se espera en Chile con sus vecinos, aunque como proceso dentro de los términos que define la securitización.

Para ello se hace una revisión de conceptos y términos, y algunos aspectos del contenido de política pública que involucra, desde una perspectiva constructivista, cifras expresadas en gráficos 
de diversos tipos de estupefacientes. Los resultados apuntan a explicar cómo la instalación del paradigma de la securitización hace posible la expansión de potenciales nuevos amenazas y desafíos no convencionales sobre las fronteras, que a su vez justifican que políticas públicas de control sean realojadas en determinadas agencias de seguridad nacional.

Para reflexionar acerca de este tema, nos aproximamos desde una perspectiva crítica de las relaciones internacionales con los autores de la Escuela de Copenhague, quienes han argumentado que las nociones de seguridad, inseguridad y amenaza, como todo concepto, implican un uso político a través de la enunciación de discursos, construidos por los Estados y que responden a sus intereses concretos, $y$ responder así a la identificación de ciertos temas objeto de seguridad (Wæver, 1995). Los discursos emanados de la autoridad, por tanto, implican ideas de seguridad acotados a grupos que tienen una posición predominante en las relaciones de poder. Estos discursos "[...] no son el producto de evaluaciones objetivas ni de constructos analíticos sobre las amenazas a la seguridad sino que son consecuencia de estructuras y procesos históricos, de la lucha por el poder y del conflicto social" (Tickner, 2008, p. 5).

Así, diferentes actores se comportan de acuerdo con diversos discursos o marcos de significado de seguridad (McDonald, 2008, p. 62). Por tanto, el problema de seguridad es definido por las élites políticas que tienen la posibilidad de hegemonizar el sentido que se le atribuye a la seguridad en un momento dado. Barry Buzan (1991) plantea que es necesario tener en cuenta la multiplicidad de objetos referentes de la seguridad; esto es, la seguridad se puede referir unas veces al Estado, otras al sistema internacional y en algunos casos al individuo concreto, y es por ello mismo que la seguridad tiene varios sectores donde se despliega de manera paralela y simultánea.

Por ejemplo, referido al Cono Sur, se encuentran las rivalidades fronterizas históricas (Fernandois, 2004), normalmente ya zanjadas o reeditadas por litigios jurídicos emprendidos por países de esta zona geográfica, muchas veces asociadas a otros fenómenos como el contrabando y el narcotráfico que acontece en las franjas fronterizas de países productores y consumidores de estas sustancias, y que a su vez coincide en el hecho de que en estos mismos países existan zonas francas que se constituyen como polos de atracción del contrabando allende la frontera. Con ello, lo que buscan las élites de turno es construir una amenaza vecinal que en muchas ocasiones -en el caso del Cono Sur-, producto de la distensión y el cambio de la agenda regional desde los años 90, ya no la constituyen de manera verificable (Ovando, 2009 pp. 236-238). En efecto, Fuentes (2008) señala que estas amenazas pueden surgir por dos vías: la persistencia de la geopolítica tradicional en las percepciones de las élites $\mathrm{o}$, deliberadamente, por su ins- 
trumentalización. Una tercera posibilidad, se asocia al vínculo entre litigios fronterizos pendientes y el aumento del contrabando en las fronteras y a la militarización de la agenda (narcotráfico y contrabando) ${ }^{1}$. Esta se refiere a que una comunidad política para tratar algo como una amenaza existencial a la seguridad habilita la adopción de medidas urgentes y excepcionales (Wæver, 1995). Dicho de otra manera, seguritización implica que una comunidad política otorga tratamiento especial a un asunto determinado, dando pie a la adopción de medidas urgentes y excepcionales para abordarlo (Arratia, 2016).

Chile es uno de los países más abiertos del mundo comercialmente (Aranda y Riquelme, 2011) y ha favorecido la reducción de documentos para el tránsito de personas en periodos inferiores de tres meses $^{2}$. Simultáneamente, existen mayores controles sobre la migración y el movimiento humano que, si bien no intentan detener, sí pretenden regular y seleccionar el tipo de desplazamiento consentido.

Así, pues, en este artículo, en primer lugar, se ahonda en aspectos teóricos relacionados con el proyecto global liberal y la emergencia de la teichopolítica. Dentro de este apartado se profundiza en la noción de frontera y seguridad: el control del acceso que conlleva. Luego, se cotejan dichos argumentos a partir de la interpretación del Plan Frontera Norte, desde el supuesto "la cuestión del otro". Finalmente, se adentra en lo referido a tecnología y seccionalización del territorio.

\section{El proyecto global liberal y la emergencia de la teichopolítica}

La globalización occidental ha modificado sustancialmente las pautas políticas, económicas y sociales con las que la humanidad se ha regido en los últimos 30 años. La integración de economías, el ritmo acelerado de cambio y la revolución de las tecnologías hablan de un epifenómeno de "larga duración", aunque cualitativamente distinto. Fundamentalmente, debido a que el proceso de intensificación de las interconexiones globales ha producido sentidos opuestos, integración-fragmentación, homogenización-diversificación, mundialización-localización.

1 Otra se refiere a la complejidad de abordar el problema del narcotráfico y contrabando de manera conjunta entre los países afectados, los mismos que mantienen litigios fronterizos: "por un lado, la nueva agenda de seguridad genera incentivos para el acercamiento y la cooperación, a pesar de las disputas territoriales latentes, mientras que, por otra parte, debido a la visión negativa y de desconfianza frente al 'otro' que caracteriza la relación de Perú y Bolivia con Chile [...] ha traído consigo nuevos espacios de desencuentro entre los tres países" (García, 2015, p. )

2 Argentina y Chile han realizado avances a este respecto. Por el Tratado de Maipú de 2009 las presidentas de Argentina y Chile, Michelle Bachelet y Cristina Fernández, se comprometieron a adoptar medidas para favorecer la circulación y residencia de nacionales en los territorios de ambas partes y adoptar medidas para armonizar las legislaciones en materia de migraciones y previsional. 
Es decir, el concepto de globalización implica "no solo la ampliación del alcance de nuestras relaciones sociales a límites planetarios, sino también a la forma en que apunta a la integración espacial del mundo a través de una mayor comunicación y el comercio" (Featherstone, 2002, p. 1).

Desde esta perspectiva, hay que recordar que ya desde los años 70, Keohane y Nye (1971) precisaron que las interacciones globales se referían a la acelerada transferencia de tecnología y transporte, intensificación de todo tipo de comunicaciones y finalmente la libre circulación financiera. $\mathrm{O}$, como plantea Stiglitz (2002), este proceso apunta:

[...] a la integración más estrecha de los países y los pueblos del mundo, producida por la enorme reducción de los costes de transporte y comunicación, y el desmantelamiento de las barreras artificiales de bienes, servicios, capitales, conocimientos y (en menor grado) personas a través de las fronteras. (p. 37)

Saskia Sassen, por su parte, sostiene que la globalización debe entenderse también como un proceso que reside en el interior del Estado nación, esto es, procesos de cambio que situados en un territorio nacional:

[...] forman parte de la globalización porque incorporan redes o entidades transfronterizas que conectan múltiples procesos y a actores locales o 'nacionales', o bien porque se trata de cuestiones o dinámicas que se registran en un número cada vez mayor de países o ciudades. (Sassen, 2007, p. 4)

Hobsbawm (2008) afirma que:

[...] un planeta neoliberal exige la libertad transnacional de movimientos para todos los factores de la producción, pero no existe total libertad de movimientos para la mano de obra, pese a que, dado el abismo que separa el nivel salarial de los países ricos y pobres, incontables millones de pobres del mundo quieran migrar a economías desarrolladas. (p. 39)

Como se señaló, la teichopolítica apunta a la política de aparente cierre de las fronteras a través del levantamiento de barreras físicas, ya sean alambradas o murallas. Rosière y Jones (2012) señalan que los ataques terroristas del 11 de septiembre de 2001 constituyeron un punto de inflexión político que provocó un giro de la globalización desde un proceso de apertura de las fronteras a otro de ciertas restricciones.

Así, se puede evidenciar la paradoja del universo en apariencia "globalizado", es decir, sin fronteras -la ficción globalizadora, como refiere Ferrer (1998, p. 167)- donde se construye todo tipo de clausura de fronteras para prevenir la permeabilidad de los límites físicos a la movilidad humana. Lo anterior supone que el movimiento masivo de personas o la universalización de la justicia han sido consecuen- 
cias no deseadas del desdibujamiento de las fronteras nacionales que conlleva el globalismo económico. Las teichopolíticas contribuyen entonces a la construcción de una globalización segmentada. Desde esta perspectiva, parafraseando a Hobsbawm (2008), incluso los países más pequeños son rocas que quiebran las oleadas de la globalización $n^{3}$. No es que estos sistemas corten el flujo, más bien posibilitan la circulación constante bajo un estricto control que permite filtrar el movimiento mediante la identificación de qué y quiénes se desplazan a través de las fronteras.

Históricamente, la razón principal, los fundamentos de la teichopolíticas se asentaron en una política de seguridad:

\begin{abstract}
Es decir, como una forma para protegerse de dos grandes amenazas: la militar y la migratoria. La preocupación militar era antigua, como la gran muralla china o el limes romano. La preocupación migratoria es mucho más contemporánea, aunque existía en el momento del Imperio Romano. (Rosière, 2011, p. 153) ${ }^{4}$.
\end{abstract}

Un caso histórico corresponde al Imperio romano que desde la segunda centuria fortificó sus fronteras, en lo que Edward Luttwak (1976, p. 4) ha calificado como segundo sistema defensivo de fronteras científicas; es decir, una política ordenada y sistemática respecto a las fronteras y las relaciones exteriores capaz de integrar la diplomacia, las fuerzas militares, las redes de caminos y las fortificaciones para servir a un único objetivo: preservar la seguridad territorial romana. Una primera afirmación apunta a que Roma había rebasado el apogeo de su poder y se estaba encerrando detrás de sus fronteras, renunciando implícitamente a la expansión hegemónica. Se trazaba entonces una separación entre la Roma civilizada y la alteridad bárbara. La estrategia de perímetro de defensa requirió inversiones colosales en cada segmento del limes, o límites fronterizos romanos, con barreras continuas o discontinuas -según fuera la naturaleza de la amenaza- combinando redes de caminos, grandes y pequeños fuertes, torres de vigilancia y medios de alerta temprana, y operando mediante señales de humo. Los elementos materiales eran solo el esqueleto del sistema defensivo que contemplaba patrullaje permanente, intercambio y sobre todo una intensa labor diplomática.

El grado de variabilidad de la naturaleza del desafío a la seguridad fue medida de acuerdo con la efectividad de las barreras en escenarios de baja

\footnotetext{
3 El historiador británico complementa "Ha habido algunos intentos ocasionales de contrarrestar la fragmentación política del globo por medio de zonas de libre comercio, sólo la Unión Europea fue más allá de sus primitivos objetivos económicos. Y ni siquiera ella muestra signos de convertirse en el Estado europeo federal o confederal que imaginaban sus fundadores" (p. 38).

$4 \quad$ La traducción es nuestra.
} 
intensidad (infiltraciones o incursiones rápidas) o de alta intensidad que suponen invasiones de mayor escala (Luttwak, 1976, p. 61).

En áreas que no estaban limitadas por accidentes naturales, grandes cursos hídricos o inmensos desiertos, un cordón de fronteras inelástico permitía prevenir ataques aislados y masivos, resolvía la contradicción entre concentración o dispersión de fuerzas, puesto que:

Era capaz de ofrecer seguridad preclusiva contra amenazas de baja intensidad utilizando una pequeña fracción del total de su fuerza, mientras que preservaba la capacidad bélica del ejercito por entablar combate de frente amplio con el total de su fuerza. (Luttwak, 1976, p. 75)

Lo nuevo para Rosière es que muchas de las actuales barreras no tienen propósitos exclusivamente defensivos, sino que buscan controlar el movimiento humano percibido como marea de emigrantes que desde países pauperizados intentan asentarse en países civilizados, en un fenómeno típico de la sociedad de riesgo de la nueva modernidad, si se sigue a Beck (2006). Por "endurecimiento" de las fronteras Rosière y Jones (2012) se refieren a la construcción de diversas tipologías de sistema de cierre, incluyendo toda clase de muros o vallas, para prevenir la entrada no deseada o los flujos de inmigración ilegales o indocumentados. Endurecimiento no significa el cierre absoluto, sino más bien el intento de controlar el flujo humano de los movimientos transfronterizos para dirigirlos a los puntos de vigilancia y seguridad que filtran la circulación. Este proceso de endurecimiento generaría un espacio asimétrico debido a que el poder de decidir sobre dichas distinciones es monopolizado por el país con mayores recursos, mientras que el otro se convierte de facto en el separado.

Pero tampoco dicha dimensión es completamente nueva, si se atiende a construcciones históricas como la Gran Muralla China o el Limes Romano de Alto Rhin.

\section{Frontera y seguridad: el control del acceso}

El concepto tradicional de Estado-nación asume que la frontera es la delimitación de un territorio que supone una serie de rasgos comunes a las comunidades insertas en él, espacio donde además el Estado tiene el pleno ejercicio de su soberanía. El aspecto central de dicha definición es que la frontera expresa una dimensión geopolítica de esta. La noción de frontera como contenedor y delimitador de un Estado nacional que ejerce su soberanía en un determinado territorio ha ido sumando fuertes críticas, entre otras, por la emergencia de procesos de orden global con impacto en lo local, que hace que los fenómenos que antes tenían un carácter nacional lleguen a transformarse en problemáticas que desbordan las fronteras estatales (Guillén, 2001; Medina, 2006). Asimismo, 
la frontera se ha ido transformado en los últimos veinte años desde un espacio delimitador a una membrana porosa que hace surgir identidades que ya no están vinculadas con las nacionales (Grimson, 2004; Sassen, 2007).

Estas transformaciones sobre la noción de frontera han repercutido en la forma como los Gobiernos nacionales y locales dan cuenta de su presencia en estos espacios fronterizos, a fin de controlar/restringir la circulación de los flujos comerciales y de personas que demandan, como señala Bigo (2011), la puesta en marcha de distintas redes de información y cooperación entre instituciones, con el fin de filtrar, limitar o facilitar dichos flujos, pero también para estimular la cooperación en un espacio fronterizo caracterizado por una importante población autóctona que ha ido haciéndose una con el espacio que habita, para construir iniciativas tendientes a mejorar sus posibilidades de desarrollo con una lógica transfronteriza (Bigo, 2011).

De esta manera, la frontera se ha ido trasformando, por una parte, en una foco de atención de agencias estatales y no gubernamentales para emprender iniciativas de desarrollo, las que trascienden la frontera como límite nacional que hay que resguardar, para transformarse en iniciativas que buscan la cooperación y la integración en una escala multinivel, orientadas a alcanzar un desarrollo más integral de las comunidades que la habitan y que además se esfuerzan por posicionarse de manera competitiva en los procesos de orden mundial, desde cuestiones de orden económicos, culturales, ambientales y políticos, entre otros.

Pero, así como la frontera adquiere una dinámica de integración y cooperación, paralelamente demanda mayores dispositivos de control de la supervisión del transporte de mercancías legales e ilegales, siendo estas últimas la mayor preocupación en lo que se refiere al espacio fronterizo del cual es objeto este artículo: el Norte Grande de Chile y sus regiones de Arica y Parinacota, Tarapacá y Antofagasta. Esta preocupación especial por la frontera en cuanto delimitación y espacio fronterizo tiene su origen y justificación en la dinámica que ha adquirido el tráfico de drogas proveniente de dos de los mayores países productores de clorhidrato de cocaína y sus derivados: Perú y Bolivia. Esta situación particular que ha ido adquiriendo el tráfico de drogas a nivel mundial y el fenómeno más global que es el crimen transnacional (Lee, 2011; Santana, 2004) ha colaborado con una creciente percepción de desconfianza hacia el "otro", nuestros países vecinos, que hace más compleja las relaciones trasnfronterizas.

De igual manera, otros fenómenos de orden internacional acrecientan estas percepciones basadas en la incerteza respecto de la alteridad. En tiempos de crisis o incertidumbre, la percepción de riesgo contra los modos de vida establecidos aumenta. El tipo de fórmulas para prevenir las amenazas descritas contra la seguridad física o el bienestar moral de una población es la clausura 
de los espacios vecinos o fronterizos: las teichopolíticas. En la actualidad, en las áreas fronterizas siempre se dan dos lógicas: la cooperación y el control. De existir una sensación de amenaza se puede llegar a provocar la denegación de acceso fronterizo cuya mayor expresión son precisamente las teichopolíticas. Y aunque esta tiene manifestaciones evidentes en la construcción de barreras físicas, existen otras expresiones menos visibles de clausuras en los espacios fronterizos para asegurar la autoridad del Estado o de una alianza de Estado: el minado de los territorios que comprenden zonas limítrofes que hayan tenido conflictos militares en ciernes, ya sea a través de escaramuzas o intentonas fallidas, como es el caso de Chile, y Perú y Chile y Bolivia durante la segunda mitad del siglo XX (Ovando Santana, 2012; Aranda y Salinas, 2015).

Después de los ataques en Nueva York y Washington el 11 de septiembre de 2001, pero aún más a partir de la colisión de intereses que supuso la nueva intervención militar iraquí ${ }^{5}$, fue reforzada una política de seguridad por parte de Estados Unidos denominada "doctrina de ataques preventivos", complementada por la erección de muros en diversas partes del mundo, en un estilo de hacer política, la segmentación, que ha sido seguida por otros Estados.
Los fenómenos que se describieron en este apartado tienen un correlato directo con las transformaciones que han ido ocurriendo en el concepto y la práctica de la seguridad, discusión que ha girado desde mediados de los años 50 en torno a las teorías clásicas de la disciplina de las relaciones internacionales, como realismo, liberalismo, constructivismo, entre otras. En esta línea la noción neorealista de seguridad asume que todas las unidades de la política global tienen solo una identidad relevante, la de Estados autointeresados, Estados que abordan la seguridad como un dilema individual que requiere políticas militares (Ovando Santana, 2012, p. 202), mientras que en los últimos diez años la reflexión ha ido girando en torno a distintas dimensiones que definen o intervienen en la seguridad (humana, medioambiental, económica, etc.). Así, por ejemplo, la seguridad humana, en cuanto el ser humano como referencia central del análisis, ya no se entiende "exclusivamente en términos de amenazas externas a las naciones bajo la forma de ataques militares [...] [ pues estas son] solo un tipo de amenaza a eliminar, neutralizar o evitar" (Shearing y Wood, 2011, p. 16), aportando entonces dimensiones que anteriormente se consideraban parte de otros marcos analíticos como la economía, la salud o el medioambiente. En este sentido, se produce un proceso de securitización.

La idea de choque entre la potencia hegemónica y potencias regionales de otras áreas por la cuestión iraquí en el seno de Naciones Unidas es trabajada en Thakur y Sighu (2006). 
Sin embargo, a la vez que la seguridad amplía sus componentes y dimensiones de análisis, incorpora una nueva lógica de administración de la seguridad que no reside solo en el Estado como administrador de la fuerza de manera monopólica, sino también en los hechos ya mencionados sobre los atentados terroristas en 2001, lo que se ha traducido en que los Gobiernos han "reclamado formas extraordinarias de autoridad y capacidad coercitiva a través de nuevas leyes, y la inyección de nuevos recursos humanos y materias, especialmente tecnológicos" (Shearing y Wood, 2011, p. 16).

Asimismo, la complejidad de la administración de la seguridad se ha visto desafiada a enfrentar la criminalidad con un carácter transnacional. Así, por ejemplo, Mónica Serrano (2005) reflexiona acerca de las dificultades de definir académicamente el crimen transnacional, cuestión que está ligada en parte a lo que el Estado establece como crimen o delito, por tanto, lo que se declara como la esfera de lo criminal. En este marco general, el narcotráfico resulta ser solo una expresión de dicho fenómeno de alcance mundial, que además tiene la particularidad de ser una práctica de orden delictual, pero con una lógica de economía capitalista, como lo señala Santana (2004):

[...] el narcotráfico o el tráfico de drogas responde sobre todo a la lógica y al interés de la economía capitalista hoy globalizada que se concibe esencialmente como el sistema de producción de bienes y servicios que tiene como fin [el enriquecimiento y no las necesidades humanas]. (p. 25)

Esta instrumentalización en ocasiones responde a las respuestas a la ampliación de las amenazas propias de la noción de seguridad humana extendida y a la incapacidad de los Estados de la región para hacerle frente de manera adecuada y sin recurrir a la coacción. Es el caso de la erradicación del tráfico de drogas y la violencia urbana, el control de la migración compulsiva, la degradación del medio ambiente, la crisis económica, entre otras nuevas amenazas que hacen hincapié en la seguridad del individuo o la seguridad humana (García y Rodrigo, 2008). Por tanto, el problema en torno a la instrumentalización de las amenazas radica en "decidir que todo problema de seguridad conlleva el riesgo de 'seguritizar' su respuesta a través del uso de la fuerza pública o fuerza militar, sin considerar la esencia o naturaleza del problema a enfrentar" (Griffiths, 2008, p. 20).

Simultáneamente, el Estado de Chile ha adoptado un enfoque abstencionista -o prohibiocinista- respecto del uso de sicotrópicos que tiene por premisa la consideración del consumo de drogas como razón principal de los daños asociados a esta, por lo que aspira a una sociedad libre de drogas (Hurtado 
y Sáez, 2004, p. 9) ${ }^{6}$. De esta manera, la prevención de dicha "amenaza" pasa a ser una política pública central que es respondida evitando la internación en territorio nacional chileno de ciertas sustancias mediante, en este caso, la implementación de una teichopolítica que eleve los niveles de control. Es el caso del plan Frontera Norte.

\section{Plan Frontera Norte}

\section{Supuestos del plan: la cuestión del otro}

Se entiende que la globalización significa la competencia por los mercados globales, donde las ventajas comparativas siempre son locales. Como sostiene Ahmad (2004, p. 184), existen visiones que muestran que pueden coexistir sistemas económicos y sociales diferentes dentro de la economía global, todos con su propio conjunto de valores compartidos, prioridades, objetivos comunes y zonas de la cooperación. Sin embargo, cada uno puede poseer su característica única y su capacidad para aplicar diferentes caminos y explorar nuevas vías para hacer frente a los desafíos cada vez más emergentes. En el área fronteriza siempre se dan dos lógicas: la cooperación y el control, que intentan mantener un flujo constante.
En la eventualidad de que las amenazas aumenten de nivel, el control se hace más relevante. De volverse una amenaza máxima, en cuanto a intensidad y envergadura, puede llegar a provocar una denegación parcial de acceso fronterizo bajo formas de teichopolítica, que permita un flujo en escrutinio para seleccionar movimiento e intercambio.

Para Robertson (2007) la globalización, junto con el hecho de propiciar la sensación que se está viviendo un mundo abierto y en red, también incrementa las percepciones de amenazas provocadas por extraños o extranjeros. Es la llamada extranjeridad (strangeness). "El aumento de securización de nuestras vidas exacerba nuestro sentido de la alteridad (la amenaza planteada por el otro): el mundo se vuelve familiar pero está lleno de extraños" (Rumford, 2013, p. 11).

Bernhard Waldenfels (2009, p. 30) identifica tres sentidos de las expresiones Fremd (extranjero) y Frenheit (extranjeridad):

En primer lugar, Frend refiere a lo que se encuentra fuera del dominio propio (ver externum, extraneum, peregrinum, étranger, foreing); también lo que pertenece a otro y finalmente lo que es de un género extraño. De este modo, lo

En el modelo de Hurtado y Sáez (2004) el otro enfoque es de reducción de daños, que distingue entre drogas duras y blandas, entre uso esporádico y abusivo, colocando los énfasis en ciertos comportamientos riesgosos como el uso común de jeringas o el consumo indiscriminado de altas dosis. 
extranjero se distingue de lo propio a partir de tres aspectos de "lugar", "posesión" y "género" (Mena, 2012, p. 8).

En la actualidad las economías globalizadas requieren una relevante cantidad de mano de obra disponible. Sin embargo, las barreras físicas que impiden su libre circulación imprimen una alta dosis de restricciones del tipo de la aludida teichopolítica (de los países desarrollados y sus aliados), constituyendo una contradicción con la proclamada economía global y la declinación de los Estados nacionales.

Dado el abismo que separa el nivel salarial de los países ricos y pobres, incontables millones de pobres del mundo quieren migrar a economías desarrolladas [...] Ningún gobierno democrático de los países desarrollados puede hacer a un lado la resistencia masiva de su pueblo contra la inmigración irrestricta, resistencia basada en razones tanto económicas como culturales. (Hobsbawm, 2008, p. 39)

Abordado el sentido económico de esta política de separación, se sugiere ir más allá de las consideraciones estrictamente económicas. Culturalmente, las teichopolíticas son también una expresión de miedo o rechazo a la alteridad. El inmigrante puede res- ponder al estereotipo de trabajador no calificado, pasando por un mendigo que profita de los sistemas de seguridad social del país receptor hasta un potencial terrorista.

Como explica Robin (Robin y Cuevas Meza, 2009),

[...] si el miedo es de tipo comunidad-extranjero, las elites siguen tomando las iniciativas y cosechan los mejores beneficios. Designados protectores de la seguridad de una comunidad, determinan qué amenazas son las más importantes y dan mayor relevancia a Irak, por ejemplo, que a Corea del Norte, al terrorismo islámico que al terrorismo local. (p. 342)

El miedo al otro explica que dos décadas después de la caída del Muro de Berlín, el mundo sigue erigiendo barreras que controlan/separan a diversos colectivos humanos. Chile no es la excepción, aunque el minado fronterizo esté siendo removido en aquella zona que experimentó una guerra decimonónica ${ }^{8}$. Al 31 de marzo de 2011 el Ministerio de Defensa de Chile afirmaba a través de su ministro, Andrés Allamand, que:

[...] de los 183 campos minados que existen en Chile, 50 ya han

Robin cita a Salim Muwakkil.

8 Las áreas minadas fueron reconocidas en el Informe de Transparencia referente a la Convención sobre la prohibición del empleo, almacenamiento, producción y transferencia de minas antipersonal y sobre su destrucción. 
sido intervenidos y de las 16 áreas de peligro se ha trabajado en 6 de ellas. Hasta la fecha se han detectado y destruido 40.845 minas -antipersonales y antitanques- logrando un avance del 22,47\%. (Ministerio de Defensa Nacional, 2011)

Mediante dicha declaración, Chile asumió el compromiso de pasar a ser un país libre de minas para 2020, y cerró así una etapa de teichopolítica que prevenía potenciales ataques militares desde los estados vecinos. Sin embargo, en este cuadro se erigieron otras potenciales amenazas provenientes del tráfico de drogas y contrabando de mercancías.

El presidente Sebastián Piñera enunció los nuevos ejes de seguridad pública en su cuenta presidencial anual del 21 de mayo de 2012, en la que refería las partidas presupuestarias fiscales 2013, especificando que una de ellas era el Plan Frontera Norte, programa orientado a detener amenazas no convencionales provenientes del crimen organizado, el tráfico de drogas y las migraciones ilegales con un origen potencial en el límite con Perú y Bolivia, lo que equivalía a reforzar las medidas de seguridad en la I y XV Región ${ }^{9}$.

De esta manera, al tradicional control de fronteras derivado del ejercicio ordinario de la soberanía estatal se adicionó un nuevo criterio que puede ser descrito como enfoque de seguridad ampliada. El giro en la naturaleza tradicional de la disuasión desplegada por las Fuerzas Armadas expandió el esquema de seguridad restringido, basado en las tradicionales amenazas provenientes de los Estados vecinos. Fue prefigurado en el borrador de la Estrategia Nacional de Seguridad y Defensa de Chile 2012-2025, que presentó el actual Gobierno del presidente Piñera. Puede rastrearse el origen de este dispositivo securitario en los planes brasileños y argentinos de seguridad, control de fronteras y espacios en zonas permeables al crimen internacional, y en el tráfico de estupefacientes del presidente Lula (Sistema de Vigilancia en la Amazonía [SIVAM], 2004) y la presidenta Cristina Fernández (Plan Escudo Norte, julio de 2011). Estas posiciones habrían sido fortalecidas en junio de 2011 por la implementación por parte de Brasil del Plan Estratégico de Fronteras (PEF), que significó el despliegue de recursos militares y tecnológicos militares en la lucha contra el narcotráfico en la frontera con Bolivia, Paraguay y Perú, que incluía radares y vehículos aéreos no tripulados. El referido programa argentino con idénticos objetivos a su símil brasileño dio inicio al mes siguiente con la instalación de

\footnotetext{
"El contexto global de la seguridad de todos los países del mundo ha cambiado. Hoy trasciende el ámbito tradicional de la Defensa, que es el resguardo de la soberanía, el territorio y el mar de nuestro país; conforme al surgimiento de nuevas amenazas se amplía y se extiende hacia temas que no eran parte tradicional de lo que se entendía por el concepto de Defensa. Entre estas nuevas amenazas cabe destacar el tráfico de armas, el tráfico de drogas, el crimen organizado, la piratería y muchas más".
} 
26 radares en la frontera con Brasil, Bolivia y Paraguay. Dichas acciones complementaban la legislación que aprobaba el derribo de aviones del origen referido y que se dedican al transporte de narcóticos.

Dicho cambio recibió un cuestionamiento inicial por involucrar a las Fuerzas Armadas en temas atingentes a la seguridad doméstica, como producto de una visión sobredimensionada de los riesgos inherentes a la globalización. Sin embargo, mucho más contundente fue una segunda crítica que apunta precisamente a una visión amenazante de la alteridad. En este caso, hay una extrapolación de las prevenciones respecto de las medidas frente a actores no estatales bajo lógicas estatales. Es decir, la amenaza sigue teniendo su origen en Bolivia y Perú, lo que Garay describe como un desenfoque entre la naturaleza convencional de la disuasión que se suma, pero no es reemplazada con este enfoque de seguridad ampliada, incrementando por ende las fricciones vecinales.

Esta perspectiva tiene su origen fuera de la región, en las administraciones de Ronald Reagan y George Bush, quienes adoptaron una estrategia de baja intensidad para enfrentar el tema del narcotráfico (Salazar Ortuño, 2008, p. 194), el corolario a la caída de la Unión Soviética, que dejó sin rival a Estados Unidos, que llenó dicho espacio con la emergencia de las amenazas asimétricas ${ }^{10}$. La primera propuesta llegó desde el Pentágono dirigido por el secretario Richard Cheney, que cuestionó la negativa para utilizar equipo y soldados en la lucha antinarcóticos. Ante el recorte presupuestario producto de la disminución de desafíos globales, Cheney apostó por autorizar la participación de las Fuerzas Armadas mejor equipadas del mundo en la Guerra contra las drogas (Chernick, 1999, p. 39). En consecuencia, fue anunciado el "Plan Bennet" o "Estrategia Presidencial de Estados Unidos contra el NarcotráfiCo" de 1989, que sugería intervenir militarmente en y con los países productores de droga (Chepesiuk, 1999, p. 18). Conforme a lo anterior, Bush anunció la entrega de 439 millones de dólares en programas militares de colaboración con Bolivia, Colombia y Perú, una campaña andina dirigida por el Comando Sur con asiento en Panamá. En el caso que observamos, esta iniciativa significó la asistencia a las Fuerzas Armadas de Bolivia para acometer su involucramiento en la erradicación de la sustancia, lo que se tradujo en la militarización del Trópico de Cochabamba liderado por las operaciones de la Administración para el Control de Drogas (DEA, por sus siglas en inglés). Esta estrategia se mantuvo hasta que la citada agencia fue expulsada de Bolivia en 2008 por el presidente Morales, que la acusó de

10 Entre otras la inmigración ilegal, el crimen internacional y el narcotráfico. 
actividades clandestinas orientadas al derrocamiento de su gobierno ${ }^{11}$.

El plan Frontera Norte fue elaborado en diciembre de 2011 sobre la base de datos aportados por la Oficina de Naciones Unidas contra la Droga y el delito (ONUCD), que apunta al progresivo incremento de oferta de sustancias ilícitas producidas en los países vecinos a Chile, particularmente cocaína y pasta base de cocaína proveniente de Perú y Bolivia; este último sindicado como el tercer productor de cocaína en el mundo. De manera complementaria, se apoya en la evidencia cuantitativa de decomisos de drogas, que demuestran la elevada participación que tienen del total de PBC y $\mathrm{CLC}$ del total nacional, las regiones Antofagasta (27\% PBC), Tarapacá12 (24\%) y Arica y Parinacota $(8 \%)$, sumado a la relevancia que adquiere la región Metropolitana que reúne el $27 \%$ del total nacional (ver figuras 1 y 2 ).

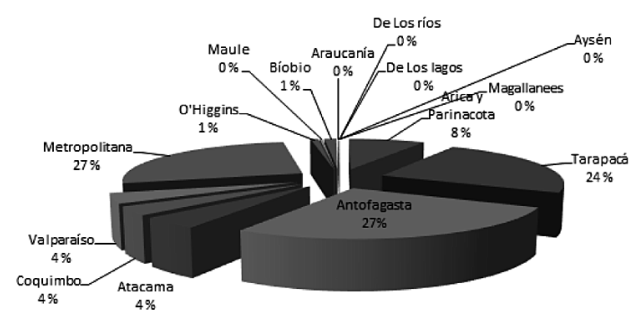

Figura 1. Distribución nacional de los demisos de PBC y CLC por regiones, periodo 2003-2012

Fuente: elaboración propia.
Según cálculos de la policía civil realizada en 2012, el país altiplánico "ha asumido un papel gravitante en los flujos de droga enviados al país", con cerca del $60 \%$ de pasta base y $75 \%$ de cocaína incautada (Saavedra, 2012). Desde el enfoque prohibicionista vigente en Chile respecto del consumo de drogas -que aspira a una sociedad libre de las mismas-, la parte principal de la lucha contra dichos ilícitos es disminuir su mercado potencial a través de un incremento del control sobre producción, tránsito y comercialización. Sin embargo, dicho enfoque no considera el punto de vista del otro, el productor, en este caso un cultor con usos y costumbres ancestrales respecto de la hoja de coca. La planta altoandina tiene una historia reciente de cultivo tolerado dentro de ciertos márgenes y siempre y cuando no sea destinado a uso como sicotrópico. Durante el Gobierno de Morales ha sido declarada "uno de los símbolos de la nueva nacionalidad" y "hoja sagrada injustamente criminalizada", y ha sido incluida en la Estrategia de Lucha contra el Narcotráfico y revalorización de la hoja de Coca, preparada por el Consejo Nacional de Lucha contra el Tráfico llícito de Droga (República de Bolivia, 2007). De acuerdo con lo anterior, la agencia boliviana estableció para el periodo 2008 y 2010 como límite a la producción excedentaria cer-

\footnotetext{
11 A pesar de lo anterior y de la negativa del Gobierno de Morales a reconocer la presencia de carteles de droga en Bolivia, el general de policía René Sanabria, encargado de respaldar actividades de contrainteligencia en la lucha contra los estupefacientes, confirma la complejidad del problema.

12 Para las regiones de Tarapacá y Arica-Parinacota, se debe tener presente que a partir de 2006 se separan ambos territorios y conforman luego dos regiones distintas con sus respectivas estadísticas de decomisos.
} 
ca de 8 mil hectáreas que se suman a las 12 mil permitidas por cada familia. La cifra contrasta con los cálculos de la Organización de las Naciones Unidas (ONU) respecto de 31 mil hectáreas para $2012^{13}$.

\section{Tecnología y seccionalización del territorio}

En el mundo contemporáneo la carrera entre el acceso y el antiacceso fronterizo comienza a despuntar en la política internacional:

Si los "accesos a" son la clave en el presente siglo, la contracara de ello es el anti-acceso, y su "socio" la negación del área, estableciendo así una relación diádica entre los que quieren mantener los accesos abiertos para ellos y eventualmente negárselos a un competidor en ascenso y quienes -en un proceso de ascenso- quieren cerrarlo a quienes proyectan poder ya que por poseer la capacidad de truncar dicho acceso se perfilan como competidores en el orden internacional de las próximas décadas. (Battaleme, s. f.)

El Plan Frontera Norte se basa en una plataforma que asegura resultados de mayores rangos de control de acceso a fronteras terrestres y marítimas de un Estado sobre la base de implementación de tecnología más el concurso de diversas agencias estatales que se coordinan para compartir información (Bigo, 2011). El referido programa supone mayor dotación de recursos humanos y físicos a las dos policías y a las Fuerzas Armadas, con el objetivo de vigilar y seleccionar el tránsito de mercancías desde y hacia Chile ${ }^{14}$, y así eliminar el ingreso de productos ilícitos (contrabando y drogas), aunque sin detener los flujos comerciales legales. Este último punto se traduce en el uso de tecnología no invasiva y portales de inspección de cargas de vehículos en pasos fronterizos y dispositivos fijos, así como móviles de control para caminos, carreteras y sectores no habilitados para el tránsito vehicular, aunque de hecho utilizados como zonas de paso. Así, restringiendo el ingreso y la circulación de drogas se pretende reducir la disponibilidad de sicoactivos.

Los Ministerios de Interior y Seguridad Pública, agencias estatales (aduanas y Servicio Agrícola Ganadero), carabineros, Policía de Investigaciones y la Dirección General del Territorio Marítimo y de Marina Mercante (Directemar) diseñaron un plan para enfrentar las difíciles condiciones topográficas

13 El incremento de la producción boliviana se origina en la creciente dificultad de condiciones de producción y comercialización de la cocaína en Colombia, y a su vez en la dimensión multifronteriza de Bolivia enclavada en el corazón de Sudamérica.

14 Cabe señalar que la información oficial de Carabineros de Chile indica que la dotación policial en las comunas de Putre, Pozo Almonte y Calama han sido de en 2011 de 4, 2 y 2 efectivos, respectivamente, y para 2012 de 4, 4 y 2 efectivos por las respectivas comunas. Lo anterior da cuenta de que en términos de dotación de recursos humanos el incremento ha sido menor. 
de áreas desérticas y semidesérticas del Norte de Chile, que han dificultado históricamente la presencia del Estado (Pinto Vallejos, 1985) y han dividido las regiones septentrionales de Chile en seis secciones. Cada una presentaría rasgos específicos que suponen medidas diferenciadas respecto a la inversión en seguridad y dotación de recursos humanos. Adicionalmente, se identificaron 192 pasos no habilitados que han facilitado la circulación de ilícitos sin medidas de control. Tanto este tipo de distinción como la organización de la inversión en control de frontera apuntan a una instrumentación política de la línea fronteriza como medio para proteger y potenciar los intereses del Estado chileno; en este caso prevenir el ingreso de drogas y evitar el contrabando de mercancías, pero sin afectar los flujos mercantiles legales. Por tanto, también se observan potenciales debilidades en la inspección ejercida en los complejos fronterizos con altos flujos de personas.

El Plan Frontera Norte estableció tres líneas de incremento de control. La primera que va desde el límite nacional hasta 10 kilómetros al interior; la segunda que corre desde el punto anterior hasta la ruta 5 norte, y la tercera orientada a la producción de información evaluada, lo que supone coordinación estatal y colaboración de organizaciones locales. En la primera línea de acción se reforzó el control y la inspección de productos y sustancias para prevenir la entrada a Chile de ilícitos. Para ello se dotó a Carabineros de Chile con cámaras termales de alta resolución capaces de detectar drogas en un perímetro de 5 kilómetros, que pueden ser escaneadas en movimiento y en forma estacionaria. Adicionalmente, se provisionó a los vehículos policiales con fibroscopios de detección de trazas de drogas y densímetros que pueden descubrir sustancias ilícitas ocultas. Los complejos fronterizos también son equipados con tecnología similar capaz de detectar desvío de precursores químicos. También se requirieron hornos e incineradores móviles para Arica y Parinacota, y Antofagasta para la rápida destrucción de droga en stock. La segunda línea implica movimiento y reacción de unidades operativas, por lo que supone vehículos todo terreno, especialmente equipados para largas estancias en zonas con condiciones geográficas y climáticamente adversas. Finalmente, la tercera línea implica que la información evaluada al interior de todo el territorio nacional chileno sea oportunamente suministrada a los equipos operativos. En este punto se previó la adquisición de tres aviones para vigilancia aérea de apoyo a las unidades terrestres. En suma, este tipo de dinámicas levantadas por las agencias estatales apunta a la construcción procesal de una frontera que distingue entre línea y zona.

Los tramos son: 1) de 55 kilómetros de vecindad con el Perú de topografía plana con alturas que van de 20 a 2100 metros. Se define por su alta complejidad, dada la facilidad de acceso entre el hito 1 y el 6, y la presencia de senderos transitables que permiten la evasión del control en los 18 kilóme- 
tros restantes; 2) enseguida 111,4 kilómetros de tramo fronterizo con Perú, cuyos primeros 48,3 kilómetros son de alta complejidad ante la existencia del paso Ancomarca, usado en contrabando y transporte de drogas, además de pueblos cuyos lugareños colaboran en la evasión del complejo de control de Visviri; 3) a continuación, 186,4 kilómetros fronterizos con Bolivia, con un sector de 44,6 kilómetros altamente complejo donde se ubican salares y pasos no habilitados, aunque con tránsito comprobado de vehículos robados, contrabando y sustancias ilícitas; 4) el cuarto tramo presenta zonas de difícil control entre los hitos 45 y 56 de una extensión de 68,1 kilómetros aledaños a lugares de acopio de drogas en Bolivia. Se constata la existencia de caminos secundarios que permiten el paso de drogas y autos robados evadiendo los controles fronterizos apostados de Colchane; 5) el siguiente tramo es visto como muy difícil, dada la presencia de varios accesos a territorio chileno que eluden los controles de Ascotan e Inacalin mediante el paso por Chiu Chiu, camino a Calama. En el tramo existe el Complejo de Ollagüe, frente al cual hay lugares de acopio de droga en Casca y Aminda. Adicionalmente, se realiza una feria en Bolivia que facilita el comercio ilegal. Por último, el Complejo Fronterizo de San Pedro había sido eludido por vehículos procedente de Jama, en el lado argentino, utilizando el cruce de Peine con acceso a la región de Atacama. Finalmente, el tramo 6) con los pasos habilitados de Jama y Sico, desde el cual se ha reconocido la internación de marihuana de ori- gen paraguayo que evita el control del complejo de San Pedro de Atacama.

\section{Evaluación de impacto}

Si se analizan las estadísticas de decomisos de clorhidrato de cocaína (CLC) y pasta base de cocaína (PBC) se puede apreciar que todas aumentan en un porcentaje significativo, salvo la región de Arica y Parinacota, que disminuye en $37 \%$ en relación con 2011 (año cuando se implementa el Plan Frontera Norte) y un $82 \%$ de disminución en relación con el período 2010-2011. Las variaciones porcentuales en las tres regiones nortinas y la Metropolitana se presentan en la tabla 1.

Tabla 1. Decomisos de PBC y CLC, variación porcentual anual

\begin{tabular}{|l|c|c|c|c|}
\hline \multicolumn{1}{|c|}{ Regiones } & $\begin{array}{c}\mathbf{2 0 0 8} \\
\mathbf{2 0 0 9}\end{array}$ & $\begin{array}{c}\mathbf{2 0 0 9} \\
\mathbf{2 0 1 0}\end{array}$ & $\begin{array}{c}\mathbf{2 0 1 0}- \\
\mathbf{2 0 1 1}\end{array}$ & $\begin{array}{c}\mathbf{2 0 1 1 -} \\
\mathbf{2 0 1 2}\end{array}$ \\
\hline $\begin{array}{l}\text { Arica y } \\
\text { Parinacota }\end{array}$ & $5,9 \%$ & $18,6 \%$ & $-82,5 \%$ & $-37,9 \%$ \\
\hline Tarapacá & $-12,3 \%$ & $-2,0 \%$ & $3,9 \%$ & $26,4 \%$ \\
\hline Antofagasta & $-46,3 \%$ & $-9,9 \%$ & $-8,1 \%$ & $56,9 \%$ \\
\hline Metropolitana & $-35,2 \%$ & $1,4 \%$ & $26,9 \%$ & $35,1 \%$ \\
\hline
\end{tabular}

Fuente: elaboración propia.

Si se pone atención a un periodo más amplio de comparación (desde 2008, ver figura2), es posible apreciar que durante 2009-2011 la cantidad de droga requisada se mantiene relativamente estable, y se destacan en las estadísticas la región de Arica y Parinacota, ya señaladas, y la región Metropolitana que se mantiene estable en 2010, pero aumenta progresivamente en los años posteriores. 


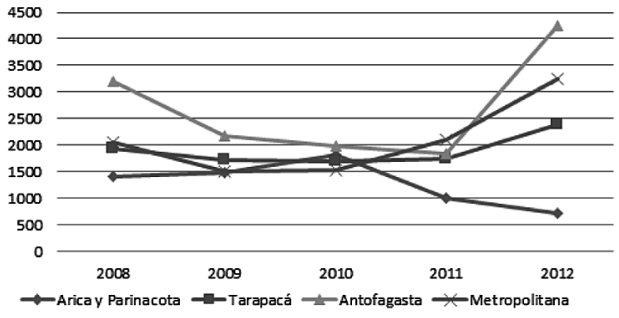

Figura 2. Decomisos de PBC y CLC, regiones del Norte grande y región Metropolitana, periodo 2008-2012

Fuente: elaboración propia.

Siguiendo el análisis de la droga requisada en procedimientos policiales, se hace necesario diferenciar el tipo de drogas, pues tanto la PBC, como el CLC tienen dinámicas distintas de incautación, lo cual puede responder a una fuente distinta de procedencia y, por tanto, también de región de ingreso a Chile. Así, se puede apreciar que al crearse la región de Arica y Parinacota el decomiso de CLC constituye uno de los más altos de las regiones nortinas, superando incluso a la región Metropolitana y destacando la fuerte caída que se produce en 2010 y 2011 (ver figura 3). Por el contrario, en las incautaciones de PBC destacan las regiones de Antofagasta, Metropolitana y Tarapacá,

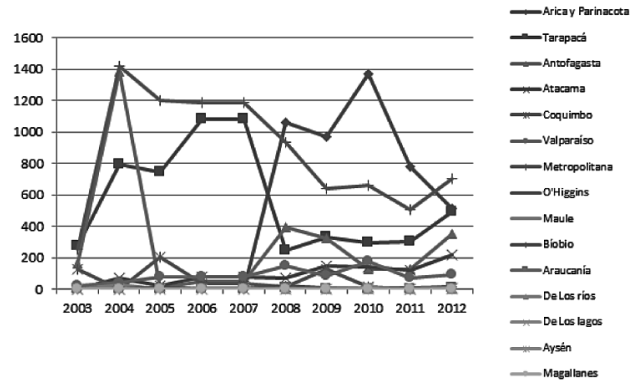

Figura 3. Decomisos de Clorhidrato de cocaína por regiones, 2003-2012

Fuente: elaboración propia. siendo también relevantes los aumentos producidos en estas mismas regiones en el periodo 2011-2012 (ver figura 4).

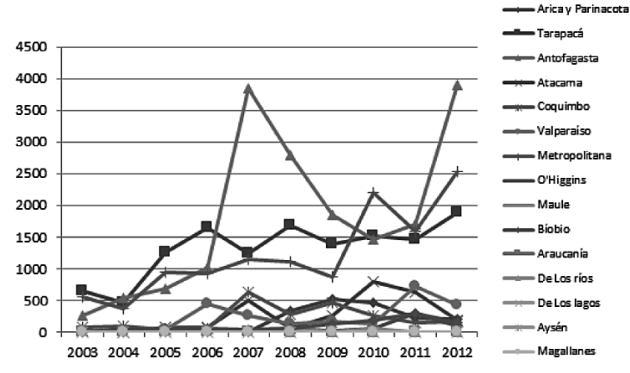

Figura 4. Decomisos de pasta base de cocaína por regiones, 2003-2012

Fuente: elaboración propia.

En resumen, las variaciones porcentuales en el decomiso de pasta base de cocaína y clorhidrato de cocaína se presentan en la tabla 2.

Tabla 2. Decomisos de CLC, variación porcentual anual

\begin{tabular}{|l|c|c|c|c|}
\hline \multicolumn{1}{|c|}{ Regiones } & $\begin{array}{c}\text { 2008- } \\
\text { 2009 }\end{array}$ & $\begin{array}{r}\text { 2009- } \\
\mathbf{2 0 1 0}\end{array}$ & $\begin{array}{r}\mathbf{2 0 1 0}- \\
\mathbf{2 0 1 1}\end{array}$ & $\begin{array}{c}\text { 2011- } \\
\mathbf{2 0 1 2}\end{array}$ \\
\hline $\begin{array}{l}\text { Arica y } \\
\text { Parinacota }\end{array}$ & $-8,2 \%$ & $40,5 \%$ & $-43,0 \%$ & $-34,1 \%$ \\
\hline Tarapacá & $35,3 \%$ & $-10,1 \%$ & $1,2 \%$ & $64,2 \%$ \\
\hline Antofagasta & $-18,5 \%$ & $-60,8 \%$ & $1,1 \%$ & $176,0 \%$ \\
\hline Metropolitana & $-32,1 \%$ & $3,5 \%$ & $-22,9 \%$ & $38,8 \%$ \\
\hline
\end{tabular}

Fuente: elaboración propia, a partir de datos de Corder y Ruiz Tagle (2013).

Tabla 3. Decomisos de PBC, variación porcentual anual

\begin{tabular}{|l|c|c|c|c|}
\hline \multicolumn{1}{|c|}{ Regiones } & $\begin{array}{c}\mathbf{2 0 0 8} \\
\mathbf{2 0 0 9}\end{array}$ & $\begin{array}{c}\mathbf{2 0 0 9} \\
\mathbf{2 0 1 0}\end{array}$ & $\begin{array}{c}\mathbf{2 0 1 0 -} \\
\mathbf{2 0 1 1}\end{array}$ & $\begin{array}{c}\mathbf{2 0 1 1 -} \\
\mathbf{2 0 1 2}\end{array}$ \\
\hline $\begin{array}{l}\text { Arica y } \\
\text { Parinacota }\end{array}$ & $34,1 \%$ & $-11,9 \%$ & $-107,5 \%$ & $-4,4 \%$ \\
\hline Tarapacá & $-21,5 \%$ & $9,0 \%$ & $-5,0 \%$ & $23,1 \%$ \\
\hline Antofagasta & $-50,4 \%$ & $-27,5 \%$ & $14,7 \%$ & $56,3 \%$ \\
\hline $\begin{array}{l}\text { Metropoli- } \\
\text { tana }\end{array}$ & $-26,5 \%$ & $60,0 \%$ & $-37,7 \%$ & $37,1 \%$ \\
\hline
\end{tabular}

Fuente: elaboración propia, a partir de datos de Corder y Ruiz Tagle (2013). 
Como se aprecia en los cuadros anteriores, es riesgoso atribuir a la implementación del plan el aumento en los decomisos de drogas, toda vez que el patrón de incautaciones en los años anteriores ha sido irregular. Esto puede explicarse por variadas razones de orden local, nacional e internacional respecto al tráfico de drogas y su dinámica criminal.

Al remitirse exclusivamente al decomiso de drogas en el periodo de implementación del plan, se puede aventurar un impacto positivo en la cantidad de narcóticos incautados. Sin embargo, también resulta aventurado asociar directamente ambos hechos en una relación causal.

En virtud de lo anterior, se considera tener en cuenta el impacto que pueda tener este plan en lo que se refiere a la inversión pública en el ámbito de la seguridad pública en las regiones fronterizas con Perú y Bolivia. En esta línea, se revisan a continuación las cuentas públicas de los Gobiernos regionales de Arica y Parinacota, Tarapacá y Antofagasta.

En la región de Arica y Parinacota, en la cuenta pública de 2012 entregada por el intendente regional, José Durana Semir, se informa que desde el año indicado están operando en la región "3 vehículos para la PDI por un monto de $\$ 55$ millones para el fortalecimiento del entorno de los complejos fronterizos Chacalluta, Chungará y Visviri" (Intendencia Regional de Arica y Parinacota, 2013, s. p.). En este mismo sentido, "Carabineros recibió 12 vehículos especiales para zonas agrestes y de bajas temperaturas por $\$ 221$ millones para mejorar sus capacidades de fiscalización y control en los destacamentos fronterizos". (Intendencia Regional de Arica y Parinacota, 2013, s. p.).

Sumado a lo anterior, se da cuenta de la adquisición de un horno incinerador de drogas móvil para el Servicio de Salud Arica, por un monto de $\$ 100$ millones de pesos, así como la entrada en operación de un equipo móvil de rayos $\mathrm{X}$ para la Policía de Investigaciones (PDI) para el control de todo tipo de vehículos y contenedores, por un monto de $\$ 799$ millones. En total, la inversión asociada al plan alcanzó 1175 millones de pesos.

En la cuenta pública de la Intendencia Regional de Tarapacá se hace referencia a la aprobación de \$1328 millones para la adquisición de equipos de alta tecnología destinados a cuidar las fronteras chilenas, inversión que comprende la adquisición de un vehículo scanner y nueve camionetas todo terreno para Carabineros y la PDI, una cámara de tecnología termal e infrarroja con capacidad de $20 \mathrm{~km}$ de alcance, destinada a la Brigada Antinarcóticos de Iquique.

La cuenta pública de la Intendencia de Antofagasta no hace referencia explícita al Plan Frontera Norte; sin embargo, se consigna el aumento en la dotación de efectivos de Carabineros en la región, además de 67 nuevos vehículos policiales, entre motos, camionetas $4 \times 4$, cuarteles móviles y camionetas con calabozo. 
En la actualidad, una derivación del plan frontera norte es el programa macro zona norte, que supone la coordinación de distintos niveles de la administración local y regional con las agencias de orden y seguridad centrales aplicados al control de tráfico de estupefaciente en la frontera.

\section{Conclusiones}

La teichopolítica es una expresión de la globalización segmentada que se asoma con mayor nitidez en el siglo XXI, y que no solo se refiere a la erección de muros, aunque dicho expediente sea su símbolo más visible. En Chile se manifestó entre los años 70 y 80 por medio del minado de zonas fronterizas como mecanismos preventivos a una invasión extranjera, en un contexto de creciente tensión fronteriza, debido a las aprensiones hacia aquellas por parte de dictaduras militares nacionalistas. En cambio, en los inicios del siglo XXI, tomó fuerza por la necesidad de crear estrategias de seguridad funcionales a la política comercial imperante en el país. Para ello se erige el Plan Frontera Norte. Mediante este mecanismo, el Estado garantiza la continuidad de los flujos comerciales consonantes con la política económica de apertura de mercado, aunque bajo una mayor supervisión que a la vez permita filtrar y controlar el flujo de personas y con especial atención contener el tráfico ilegal de mercancías y narcóticos.

La teichopolitica no es solo una estrategia de contención en la frontera a través de la selección de flujos; es también, culturalmente, una expresión de miedo o rechazo a la alteridad. Desde esta perspectiva, el caso chileno estuvo marcado por décadas por el temor hacia los países vecinos por rivalidades históricas fronterizas, señaladas más arriba. Si bien hoy en día, desde la incipiente ejecución del Plan Frontera Norte, es falaz argumentar que promueve la amenaza del inmigrante estereotipado como trabajador no calificado, que profita de los sistemas de seguridad social del país receptor, sí se puede argumentar que este plan per se sugiere una visión amenazante de la alteridad. Esta se explica desde la aplicación de medidas estatales frente a actores no estatales bajo la lógica de la seguridad ampliada y de que la amenaza -ahora por el narcotráfico- sigue teniendo su origen en Bolivia y Perú.

En efecto, esta ampliación desde las amenazas convencionales a las no convencionales en el concepto de seguridad ha impactado notablemente en la política pública orientada a mejorar la seguridad de Chile. Así, las amenazas no convencionales se han traducido en los argumentos prioritarios para generar estrategias de control de la frontera, que van más allá de las propias amenazas, lo que da cuenta de un temor a los potenciales riesgos de nuestros vecinos. Resulta fundamental, en esta misma línea, comprender que las respuestas que Chile está dando a la problemática de la seguridad interna son reflejo de procesos de orden regional que ya han tenido sus propias expresiones en países como Brasil (SI- 
VAM), modelo que sirve como antecedente para la construcción del Plan Escudo Norte en Argentina y el plan chileno objeto de este artículo.

En este sentido, se les atribuye a las fuerzas armadas la capacidad para afrontar las nuevas amenazas en contextos de estados desbordados, puesto que en el continente los militares han jugado un papel histórico en la imposición del orden interno.

Una de las prioridades de esta estrategia, habida cuenta de la compleja geografía del Norte Grande, marcada por su vasta extensión y por cientos de pasos fronterizos no habilitados además de la difícil presencia del Estado, fue la seccionalización del territorio, según ciertas prioridades y demandas de seguridad y control de flujos. Para ello recurrió al uso de tecnología no invasiva y portales de inspección de cargas de vehículos en pasos fronterizos y dispositivos fijos, así como móviles de control para caminos, carreteras y sectores no habilitados para el tránsito vehicular. No obstante su aplicación, se observan potenciales debilidades en la inspección ejercida en los complejos fronterizos con altos flujos de personas.

Finalmente, en el marco de las cuentas públicas analizadas, es posible apreciar que la evaluación hecha por los Gobiernos regionales da cuenta más bien de la inversión concretada, que del impacto que dicha inversión ha tenido en las estadísticas de decomisos de drogas y procedimientos policiales asociados al tráfico de drogas ilícitas. Lo anterior también se refleja en los informes y en el análisis que se desprenden de información perteneciente al Ministerio del Interior; antecedentes que consignan el nivel de inversión en equipamiento y dotación policial. Se reconoce, sin embargo, que una evaluación más profunda del plan requiere un tiempo más amplio de ejecución.

\section{Referencias}

Ahmad, K. (2004). The challenge of global capitalism: An islamic perspective. En J. H. Dunning (Ed.), Making globalization good: the moral challenges of global capita Oxford, New York: Oxford University Press.

Aranda, G. y J. Riquelme (2011). La política exterior de Chile desde 1990: inserción

internacional y prioridad regional. Cuadernos sobre Relaciones Internacionales, Regionalismo y DesarroIlo, 6(11), 11-41.

Aranda Bustamante, G. C. y Salinas Cañas, S. F. (2015). Minefields and Humanitarian Demining at the Chile-Bolivia Border: A Step-byStep Approach. Frontera Norte, 27(54), 123-142

Arratia, E. (2016). ¿Estrategia de seguridad pública o de guerra? guerra contra el narcotráfico (2006-2012) como proceso de seguritización Debates Latinoamericanos, 15(29). Recuperado de http://revista. rlcu.org.ar/numeros/14-29-Octubre-2016/documentos/ArratiaSandoval.pdf 
Battaleme, J. (s. f.). Cambiando el statu quo de la geopolítica internacional: el acceso a los espacios comunes y las estrategias de negación de espacio y antiacceso. Copia mimeo.

Beck, U. (2006). La sociedad del riesgo global: hacia una nueva modernidad. Madrid: Paidós.

Bigo, D. (2011). Frontières, territoire, sécurité, souveraineté. Recuperado de http://ceriscope. sciences-po.fr/content/part1/frontieres-territoire-securite-souverainete

Buzan, B. (1991). People, States and Fear, An agenda for International Security Studies in

the Post-Cold war era. Worcester: Harvester Wheatsheaf.

McDonald, M. (2008). Constructivism and security. En P. D. Williams (Ed.), Security

studies: An introduction (pp. 59-67). London: Routledge.

Chepesiuk, R. (1999). The war on drugs : an international encyclopedia. Santa Barbara: ABC-CLIO.

Chernick, M. (1999). Las dimensiones internacionales de los conflictos internos en América Latina: de la Guerra Fría (a la paz negociada en Centroamérica) a la Guerra Antinarcótica. Colombia Internacional, (41), 5-43.

Corder, A. y Ruiz Tagle, V. (2013). Infracciones penales en espacios transfronterizos. El narcotráfico en la provincia del Tamarugal,Chile. Estudios Fronterizos, 1(27), 31-63.
Featherstone, M. (2002). An introduction. En A. Mohammadi (Ed.), Islam encountering globalization (pp. 3-24). London, New York: RoutledgeCurzon.

Fermandois J. (2004). Mundo y fin de mundo: Chile en la política mundial 1900-2004. Santiago: Ediciones Universidad Católica de Chile.

Ferrer, A. (1998). Hechos y ficciones de la globalización globalización y relaciones externas de América Latina y el Caribe. Caracas: Sistema Económico Latinoamericano y del Caribe [SELA]53).

Fuentes, C. (2008). Fronteras calientes. Foreign Affairs Latinoamérica, 8(3), 12-21.

García Pinzón, V. (2015). Territorios fronterizos. Agenda de seguridad y narcotráfico en Chile: el Plan Frontera Norte. Estudios Internacionales, 47(181), 69-93.

García, C. y Ángel, R. (2008), La necesidad de redefinir la seguridad: seguridad humana, seguridad colectiva y derecho internacional. En García, C. y A. Rodrigo (Eds.), La seguridad comprometida. Nuevos desafíos, amenazas y conflictos armados (pp. 205-228). Madrid: Tecnos.

García, C. y A. Rodrigo (Eds.), La seguridad comprometida. Nuevos desafíos, amenazas y conflictos armados. Madrid: Tecnos.

Griffiths, J. (2008). Seguridad hemisférica en América Latina. Alcances y proposiciones. Escenarios Actuales, (13), 13-26. 
Grimson, A. (2004). Fronteras, naciones y región. Recuperado de http:// www.mujeresdelsur-afm.org.uy/ agenda_pos/pdf/4a_edicao/alejandro_grimson_esp.pdf_

Guillén, M. F. (2001). Is Globalization Civilizing, Destructive or Feeble? A Critique of Five Key Debates in the Social Science Literature. Annual Review of Sociology, 27, 235-260.

Herrera Cajas, H. (1998). Dimensiones de la cultura bizantina: arte, poder y legado histórico. Santiago de Chiler: Universidad de Chile, Universidad grabriela Mistral.

Hobsbawm, E. (2008). Después del siglo XX: un mundo en transición. En R. A. Lagos y R. L. Escobar (Eds.), América Latina: ¿integración o fragmentación? (pp. 29-50). Guadalajara: Fundación Grupo Mayan.

Hurtado E., P. y Sáez R., X. (2004). Políticas y programas de prevención y control de drogas en Chile. Santiago de Chile: Fundación Paz Ciudadana.

Intendencia Regional de Arica y Parinacota. (2013). Cuenta pública. Recuperado de https://www.gorearicayparinacota.cl/index.php/ cuentas-publicas/48-cuenta-publica-intendente-2013

Lee, M. (2011). Trafficking and global crime control. Los Angeles: Sistema de Apoyo a la Gestión Educacional [SAGE].

Luttwak, E. N. (1976). The grand Strategy of the Roman Empire. From the first century A. D. to the third. Baltimore: Johns Hopkins University Press.
Medina, E. (2006). Aportaciones para una epistemología de los estudios sobre fronteras internacionales. Estudios Fronterizos, 7(13), 9-27.

Mena, P. (2012). Presentación, hospitalidad y extranjeridad. Santiago: LOM Ediciones.

Ministerio de Defensa Nacional, (2011). Chile, país libre de minas para el año 2018. Recuperado de http://desminado.defensa.cl/?p=54

Nye, J. S. y Keohane, R. O. (1971). Transnational relations and world politics. Cambridge: Harvard University Press.

Ovando Santana, C. (2012). La seguridad internacional en la proyección de chile hacia el cono sur: ¿desde la doctrina de la seguridad nacional hacia la construcción de comunidades de seguridad o la emergencia de la securitización? Revista de Relaciones Internacionales, Estrategia y Seguridad, 7(2), 193-219.

Ovando, C. (2009). Hacia la complementariedad Realismo-Liberalismo: aproximación a

las relaciones chileno bolivianas desde debate ideas claves y factores materiales. Revista Enfoques, 10, 235271.

Pinto Vallejos, J. (1985). La sociedad tarapaqueña durante los primeros años de la ocupación chilena, 1879-1884. Nueva Historia, 4(1516), 107-127.

República de Bolivia. (2007). Estrategia de lucha contra el narcotráfico y revalorización de la hoja de coca 
2007-2010. Recuperado de http://www.embajadadebolivia. com.ar/m_documentos/imgdocumentos/05coca.pdf.

Robertson, R. (2007). Open societies, closed minds?: Exploring the Ubiquity of Suspicion and Voyeurism. London: Routledge.

Robin, C. y Cuevas Meza, G. (2009). El miedo: historia de una idea política. México, D. F.: Fondo de Cultura Económica.

Rosière, S. (2009). Penser l'espace politique. Paris: Ellipses Édition.

Rosière, S. (2011). Teichopolitics: the Politics of Border Closure. Si Somos Americanos, XI(1), 151-163.

Rosière, S. yJones, R. (2012). Teichopolitics: Re-considering Globalisation Through the Role of Walls and Fences. Geopolitics, 17(1), 217-234. doi: 10.1080/14650045.2011.574653

Rumford, C. (2013). The Globalization of Strangeness. Londres: Palgrave Macmillan.

Saavedra, O. (2012). Fuerte alza en internación de droga: casi se quintuplica la cocaína base. El Mercurio, C11.

Salazar Ortuño, F. B. (2008). De la coca al poder. Políticas públicas de sustitución de la economía de la coca y la pobreza en Bolivia 1975-2004. Buenos Aires: Consejo Latinoamericano de ciencias Sociales [Clacso].
Santana, A. (2004). El narcotráfico en América Latina. Mexico, D. F.: Siglo XXI, Universidad Nacional Autónoma de México [UNAM].

Sassen, S. (2007). Una sociología de la globalización. Análisis Político, 20(61), 3-27.

Serrano, M. (2005). Crimen transnacional organizado y seguridad internacional: cambio y continuidad. México, D. F.: Fondo de Cultura Económica.

Shearing, C. D. y Wood, J. (2011). Pensar la seguridad. Barcelona: Gedisa.

Thakur, R. y Sidhu. W. P. S. (2006). The Iraq crisis and world order structural, institutional and normative challenges. Recuperado de http://0site.ebrary.com.medina.uco.es/lib/ bibliocordoba/Doc?id = 10156077

Stiglitz, J. (2002). El malestar en la globalización. Madrid: Taurus.

Tickner, A. (2008). Los estados y la securitización: dinámicas de seguridad andina. En Primer Congreso de Ciencia Política. Bogotá, Colombia.

Waldenfels, B. (2009). Topographie de l'étranger: bétudes pour une phénoménologie de l'étranger 1. París: Van Dieren.

Wæver, O. (1995). Securitization and Desecuritization. En R. Lipschutz (Ed.), On Security (pp. 46-48). Nueva York: Columbia University Press. 